need to invest half that again.

A programme announced last year for joint research between industry and universities was financed from a supplementary budget, meaning that the money had to be spent in one year - a short period to develop new technologies, say MITI officials (see Nature 402, 116; 1999).

Koichi Sumikura of Tokyo

University's Research Center for Advanced Science and Technology agrees that a three-year budget will "allow rollover and avoid some wastefulness of projects whose budget must be exhausted in one year". At the end of three years, government support would end and, it is envisioned, entrepreneurs would be able to exploit the joint research.

University researchers' enthusiasm for the project is still in doubt. The lifting of some restrictions, which allowed researchers to take up executive positions in companies (see Nature 403, 589; 2000), has yet to stir much interest.

Part of the problem, says Kawaguchi, is that "universities are less demanding than in the United States, and many researchers will tell you they are simply too comfortable to take a risk in industry". The current programme is designed to allow them to develop their technologies, and perhaps gain some new research equipment, without risk.

But problems with intellectual property could lessen industry's interest in joint research. Any action taken on a patent in Japan must be agreed to by all holders. Thus, even if a university were to hold only a small share of the patent, warns one Ministry of Health official, the prospective entrepreneur "would have to deal with lengthy bureaucratic deliberations on the use of the patent".

MITI's Medical and Welfare

Equipment Industries section chief Yukiko Araki admits that, although MITI and the health ministry share the same goals, many details of funding and other procedural matters are still in need of attention.

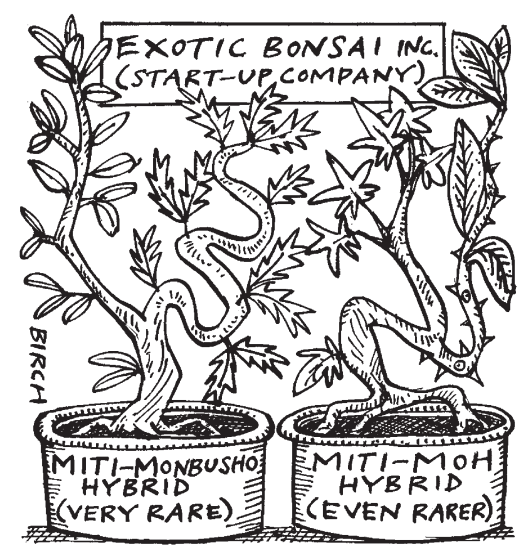

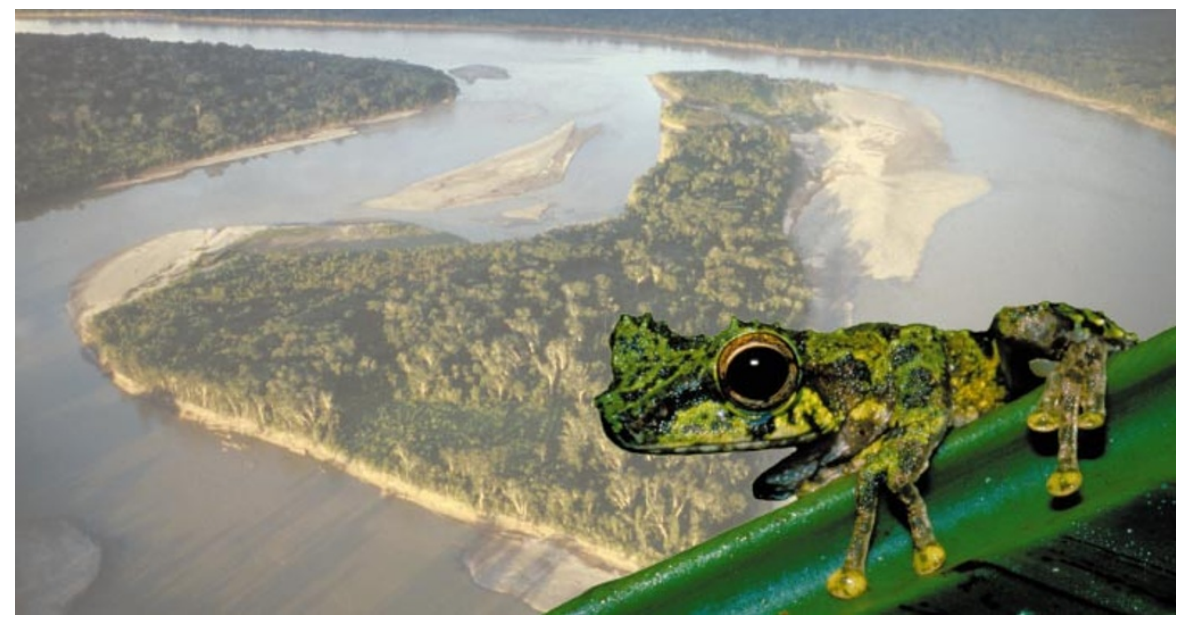

Safe? Species such as this newly discovered Indonesian frog could benefit from the biodiversity plan.

\title{
Ecologists back blueprint to save biodiversity hotspots
}

\section{Rex Dalton, Pasadena}

Eminent ecologists have endorsed a multibillion dollar blueprint for the conservation of biodiversity hotspots around the world, deflecting concerns about the scope and cost of the plan.

Conservation International (CI), a Washington-based non-profit organization invited leading lights of the biodiversity research community, such as Harvard University's Edward Wilson, to discuss the proposal at a four-day meeting at the California Institute of Technology last week.

"If we are going to have an impact on saving biodiversity, we have to approach this on a scale far beyond anything proposed before," says CI president Russell Mittermeier.

CI officials hope that philanthropists and private individuals will make the huge donations needed to support the conservation efforts. The first step towards this goal was taken recently, with the announcement of a \$75 million Critical Ecosystem Partnership Fund, which is expected to double in size within months (see Nature406, 818;2000).

The 25 biodiversity hotspots targeted for preservation under the blueprint cover $1.4 \%$ of the Earth's land area, but contain an estimated $44 \%$ of vascular plant species and $35 \%$ of all species in four major vertebrate groups. The hotspots — including areas of Latin America, Africa, Madagascar, India and Southeast Asia - were described earlier this year in an article by CI scientists and their co-workers (see Nature 403, 853-858; 2000).

Participants at last week's symposium said that conservation efforts should reach beyond these locations to save three wilderness regions threatened by forestry, mining and ranching. These are the Amazon Basin and the Guyana shield region in South
America, and the Congo Basin in Africa.

A draft document - called An Agenda to Defy Nature's End - was drawn up by the scientists to focus research programmes, develop local preservation efforts and reduce incentives for the destruction of biodiversity.

But the costs of preservation, management and running a research centre at each biodiversity hotspot could be nearly $\$ 200$ million a year in each case, CI officials say. Protecting the three wilderness areas could cost an additional $\$ 4$ billion, says Mittermeier, adding that he hopes to raise $\$ 1$ billion in private money to jump-start this effort.

CI's plan has sparked debate among ecologists, with some questioning whether there are enough data to identify the hotspots most worth saving. The meeting heard from some of the sceptics, including Andrew Dobson, an evolutionary biologist at Princeton University, and Andrew Balmford, a zoologist at Cambridge University, who have publicly challenged the proposal (see Nature 405, 393; 2000).

Stuart Pimm, a conservation biologist at Columbia University in New York who led the discussion of the blueprint, says that "a broad consensus on what needs to be done" emerged from the meeting.

But Jeff McNeely, chief scientist for the Swiss-based World Conservation Union says that CI needs to reach out to governments whose nations include the hotspots, so as to introduce more reality into its planning.

"Governments often don't like biodiversity," McNeely points out. "They are trying to build nations. I am very supportive of what CI is trying to accomplish. But if you are going to design something that works, you have to talk to the opposition."

http://www.conservation.org

http://www.defyingnaturesend.org 